\title{
Schulausschluss bei übertragbaren Krankheiten
}

\author{
Meinrad Schär, Lison Roschewski
}

Institut fur Sozial- und PräventivmedizIn der Universităt Zurıch. Sumatrastrasse 30, 8006 Zürlch

ERGeBNIS EINER UMFrage geI DEN KANTONALEN GESUNDHEITSBEHÖRDEN

\begin{tabular}{|c|c|c|c|c|c|c|c|}
\hline \multirow{2}{*}{$\begin{array}{l}\text { Antwortende } \\
\text { Kantone }\end{array}$} & \multirow{2}{*}{$\begin{array}{l}\text { Ceserzliche } \\
\text { Bestimmungen: }\end{array}$} & \multicolumn{5}{|c|}{ Daver des Ausschlusses von Schlllem } & \multirow{2}{*}{$\begin{array}{l}\text { Schulausschluss } \\
\text { von Geschwistem }\end{array}$} \\
\hline & & Diphtherie & Scharlach & Masern & Tuberkulose & andere & \\
\hline \multirow[t]{5}{*}{24} & \multirow{5}{*}{$\begin{array}{l}\text { Vollziehungs- } \\
\text { verordnungen } \\
4 \text { gestlitzt auf } \\
\text { das Eldg. Epi- } \\
\text { derilengesetz } \\
\text { Reglemente, } \\
14 \text { Bmpfehlungen, } \\
\text { Richtlinien, } \\
\text { Verordnungen } \\
\text { keine Vor- } \\
5 \text { schriften od. } \\
\text { Empfehlumgen }\end{array}$} & $\begin{array}{c}7 \\
2 \text { Wochen }+ \\
2 \text { negative } \\
\text { Abstriche }\end{array}$ & \multirow{2}{*}{$\begin{array}{l}\quad 5 \\
48 \text { Std. } \\
\text { nach Pe- } \\
\text { nicilin- } \\
\text { behand- } \\
\text { lung }\end{array}$} & \multirow{2}{*}{\multicolumn{2}{|c|}{ 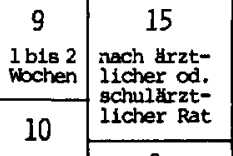 }} & $\begin{array}{l}11 \\
\text { Menin- } \\
\text { gitis }\end{array}$ & $\begin{array}{c}8 \\
\text { Diphtherle } \\
(1-2 \text { Wochen und } \\
\text { Abstriche })\end{array}$ \\
\hline & & \multirow{3}{*}{$\begin{array}{l}2 \\
\text { nur } 2 \\
\text { negative } \\
\text { Abstricice }\end{array}$} & & & & 7 & \multirow{3}{*}{$\begin{array}{c}6 \\
\text { Scharlach } \\
(2 \text { bis } 5 \text { Tage } \\
\text { und/oder Pente.) }\end{array}$} \\
\hline & & & \multirow{2}{*}{$\begin{array}{c}4 \\
2 \text { wochen }\end{array}$} & \multirow{3}{*}{$\begin{array}{l}\text { Klin. } \\
\text { Abhei- } \\
\text { lungi. } \\
\text { arztl. } \\
\text { Rat }\end{array}$} & \multirow{3}{*}{$\begin{array}{c}2 \\
\text { gemiss } \\
\text { tho-Gesetz }\end{array}$} & Hepatitis & \\
\hline & & & & & & 6 & \\
\hline & & \multirow{2}{*}{$\begin{array}{l}1 \\
1 \\
2 \text { bis } 7 \text { Tage } \\
\text { und } 3 \text { Ab- } \\
\text { striche } \\
\end{array}$} & \multirow{2}{*}{$\begin{array}{l}9 \\
\text { klin.Ab } \\
\text { hellung, } \\
\text { grztl. } \\
\text { Rat }\end{array}$} & & & $\begin{array}{l}\text { Abcaminal- } \\
\text { typhus }\end{array}$ & \multirow{2}{*}{$\begin{array}{c}6 \\
\text { Mening1tis } \\
\text { (2 Tage bis } 4 \\
\text { Wochen mit oder } \\
\text { ohne Rifampicin) }\end{array}$} \\
\hline \multirow{4}{*}{\multicolumn{2}{|c|}{$\begin{array}{l}\text { Schliessung von klasgen: } \\
\text { Wenn } 1 / 4 \text { bis } 1 / 2 \text { der } \\
\text { Schuler enkrankt ist } \\
\text { oder nach schularzt- } \\
\text { licher Empfehlung }\end{array}$}} & & & & & $\begin{array}{c}4 \\
\text { Polio } \\
\end{array}$ & \\
\hline & & $\begin{array}{c}1 \\
3 \text { wochen }\end{array}$ & \multirow{3}{*}{$\begin{array}{l}1 \\
3 \text { Wochen } \\
\text { nach } \\
\text { Penicil.. } \\
5 \text { Wochen } \\
\text { onne Pe } \\
\text { nicilin }\end{array}$} & & & $\begin{array}{c}3 \\
\text { Murmps }\end{array}$ & \multirow{2}{*}{$\begin{array}{l}2 \\
\text { andere: Polio, } \\
\text { Grippe, Mulps }\end{array}$} \\
\hline & & \multirow{2}{*}{\begin{tabular}{l}
\multicolumn{1}{c|}{7} \\
nach arzt- \\
licher od. \\
schularzt- \\
licher \\
heloung
\end{tabular}} & & & & \multirow{2}{*}{$\begin{array}{l}\text { ferrer } \\
\text { vereinzelt } \\
\text { bei per- } \\
\text { tussis }+ \\
\text { RHtein }\end{array}$} & \\
\hline & & & & & & & \begin{tabular}{l}
$\quad 5$ \\
\multicolumn{1}{c}{5} \\
gemlss urztl. \\
oder schullarztl. \\
Rat
\end{tabular} \\
\hline
\end{tabular}

die grossen zahlen bedeuten Anzahl Kantone

D1e zuständıgen Behorden aller Kantone wurden nach Ihren Kriterlen betreffend Schulausschluss bel Infektlonskrankhelten befragt. 24 Kantone haben geantwortet; 4 stützen slch auf Verordnungen des E1dgenössischen Epldemiengesetzes, 15 Kantone auf elgene Reglemente und RIchtlinien; 5 Kantone haben diesbezuglicn keine Verordnungen. Bel Tuberkulose wird in 15 Kantonen nach arztlicher Empfehlung für den betreffenden Fall und nur In 2 Kantonen nach dem Tb-Gesetz vorgegangen. Bel den hăuflgsten Infektionskrankhel ten (Diphtherle, Scharlach, Pertuss1s, Masern. Meningltis, etc.) ist der Schulausschluss uneinheltllich geregelt. In 8 Kantonen werden Klassen nach schulärztllicher Empfehlung geschlossen, wenn $1 / 4-1 / 2$ der Schuler erkrankt 1 st.

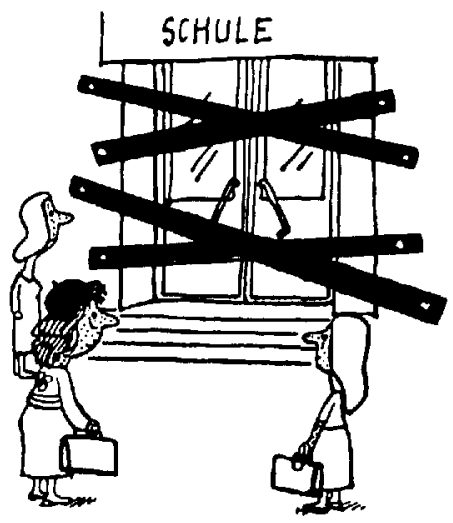

Kommentar:

In bezug auf den Ausschluss von Schulern vom Unterricht besteht elne bunte Vielfalt. Es glbt Kantone, dle keine gesetzlichen Bestimmungen haben: und anderersel ts Kantone mit detallierten gesetzlichen Bestimmungen. Interkantonal anwendbare Empfehlungen drăngen sich auf, 